\title{
The Study on Creative Tutoring Service Design to Improve Self-presentation and Learning Abilities for Kids Focusing on Visual Association and Storytelling
}

\author{
Dong Min Lee ${ }^{1}$, Hye Jung Park ${ }^{2}$, Sung Bae Cho ${ }^{2}$ \\ ${ }^{1}$ Department of Industrial Design, Kyung Hee University, Yongin, 446-701 \\ ${ }^{2}$ Smart Solution Lab, FEIT, Seoul, 137-267
}

\begin{abstract}
Objective: The goal of this study is to design a creative tutoring service, which helps children gain confidence and creativity through learning activities. Background: Nowadays most kids are growing up in a very competitive environment under their parents' zeal for education. A stressful environment can deter a child from the confident undertaking of challenges, leading to depression, anxiety, and feelings of inadequacy. Art therapy helps children work through these issues, however the process led by instructors or parents, and kids still feel anxious studying adults' face to read their thought. Method: To help children address challenges, a creative tutoring service application can provide abstract images with certain tasks instead of asking them to fill in blank areas. The tasks asked by the service system are 1) to visualize children's own experience utilizing visually associated images from given abstract images and 2) to create an illustrated story modifying and re-composing given images. Another task is to learn basic math and words with numbers and alphabets in customized colors. By completing each task children collect awards, which allow them graduate to higher levels of challenges. The outcomes from the tasks are sent to the main server system and reviewed by analysts. Those results are sent to children's parents as a text message on smart phone. Results: Visual implication using abstract images inspires children to make creative stories based on their own experience. Also, children can find their own patterns of reaching answers by using synaesthetic imagery through repetitive practices of creative thinking tasks. Conclusion: Understanding how they feel about doing tasks in certain environments and assessing them in varied situations should be carefully considered when designers approach service design for kids. By focusing on how to tutor children in creative ways, as opposed to focusing on the expected outcome, creative service applications can be designed to reduce children's stress and encourage self expression. Children are predicted to gain confidence through using the service without the concern of comparison by others. Application: The creative tutoring service needs to be developed and tested by varying types of children.
\end{abstract}

Keywords: Service design, Tutoring, Creative thinking ability, Self-presentation ability, Children

\section{Introduction}

처음부터 자신감과 창의력이 넘쳐 흐르는 사람은 극히 드 물다. 아티스트 댄 퍼잡스키(Dan Perjovschi)는 어린이의
행태에 대해 "어린 아이들에게 종이와 연필을 주면 아이들은 바로 무언가를 그린다. 하지만 10살이 넘어서면서부터는 종 이 앞에서 무엇을 할까 고민을 한다. 그림을 그린다는 것은 누구에게나 있는 타고난 재능이지만, 교육과 사회와의 과정 속에서 타고난 재능이 묻혀진다."라고 설명한다. Cohen은 어

Corresponding Author: Dong Min Lee. Department of Industrial Design, Kyung Hee University, Yongin, 446-701.

Mobile: 010-9072-1677, E-mail: mick@khu.ac.kr

Copyright@2012 by Ergonomics Society of Korea(pISSN:1229-1684 eISSN:2093-8462). All right reserved. 
린 시절 열정적으로 관심을 갖는 것이 성인기 창의력의 발단 이 된다고 말하며, 이는 어린이의 첫 학습법이 자신감 넘치 고 창의력이 뛰어난 아이로 성장하는데 있어서 얼마나 중요 한지 보여준다. Multi 또는 Convergence라는 용어는 더 이 상 Smart Device를 위한 용어만이 아니다. 다양한 능력을 갖추고 복잡해진 상황을 영리하게 이끌어 가야 하는 만능+ 융합인으로 성장해야 하는 사회적 분위기 속에서 우리나라 부모들의 교육열은 아이들에게 심각한 학업 스트레스를 안 겨주고 있다. 또한, 우리나라 어린이들은 빠르면 3 4세, 늦 으면 7세에 가정이라는 곳을 벗어나 어린이집, 유치원에서 어른 못지 않은 사회활동을 시작하게 된다. 이러한 사회생활 을 시작하게 됨으로써 낮선 무리 속에서 낮선 사람으로부터 "무엇 무엇을 해오세요", "무엇 무엇을 해보세요"와 같은 요 구를 받게 되며, 어린이가 도출해낸 결과는 그들에게 고스란 히 노출되게 된다. Haapasalo와 Treambly는 가정 및 학교 안팎의 일상생활에서 받는 스트레스를 적절히 대처하지 못 하면 정서적으로 불안하고 저조한 학업성취나 부적응 문제 를 야기하게 된다고 말한다. 이러한 아동기의 스트레스는 기 본적인 대처능력의 부재로 생기는 경우가 많으므로 단순 학 습을 위한 Task보다 자신감을 키우고 자신을 표현할 수 있 는 능력을 계발하는 과정을 반복함으로써 아이들의 궁극적 인 학습력이 향상될 수 있다. 다시 말해, 문제를 직면할 수 있게 도와줄 수 있는 환경 조성과 그 것을 해결할 수 있는 상황을 자연스럽게 만들어주는 과정의 반복이 아이들이 가 진 막연한 것에 대한 두려움과 해결 가능 여부에 대한 불안 감을 감소시킬 수 있다. 현재 이와 관련 어린이 미술 테라피 와 아동 미술 치료, 창의력 증진 독서 프로그램 등의 시장이 확대되고 있다.

테라피와 미술 치료는 명칭에서부터 아이에게 '어린이 스 트레스라는 질병을 앓고 있다는 생각과 함께 감추고 싶은 결점으로 인식하게 한다. 테라피와 미술 치료는 부모와 교사 라는 평가자들이 여전히 존재하는 구성으로 어린이에게 편 안한 환경 제공에 부족함을 보인다.

이에 본 연구에서는 완성된 작품 자체보다 아이디어나 과 정을 예술이라고 생각하는 개념 미술(Kim, 2009)을 기반으 로 하여 어린이들 스스로가 자유로운 시각으로 능동적인 판 단을 하고, 창의적으로 Task를 수행할 수 있도록 유도하는 Creative Tutoring Service Design을 제안하고자 한다.

최근 어린이와 학생들의 Tablet PC와 Smart phone 사 용이 많이 관찰된다. 이렇게 사용이 빠르게 확산되고 있는 Tablet PC와 Smart Phone 기기의 시각적, 촉각적, 청각적 인 빠르고 다양한 인터랙션은 다양한 성향의 어린이들한테 흥미를 유발시키면서 자연스럽게 집중을 유도한다. 그리하여 본 연구에서는 Smart Mobile Device를 통한 Application 의 형태로 자아표현 계발 및 창의력 증진 튜터링 서비스를
디자인하고자 한다.

\section{Direction of Creative Tutoring Service}

\subsection{Goals}

학습 초기 단계의 어린이를 대상으로 한 창의적 튜터링 서비스의 목표를 세 가지로 정리해보았다.

1) 어린이의 시각과 사고 및 판단에 대한 이해를 바탕으 로 어린이에게 특화된 서비스 개발

2) 새로운 내용을 가르치기보다 창의적으로 생각하고, 스 스로 주도해나가는 능력을 키울 수 있는 서비스 개발

3) 사회-어린이-부모의 유대적 관계 향상시켜줄 수 있는 튜터링 서비스 구조 설계 개발

\subsection{Methods}

다른 연구들에 의하면, 흥미의 형성(Formation of Interests) (Cohen, 1999), 동기 (Motivation) (Fasko, 2006), 그리고 자라난 문화(The Culture one grows up within) (Super and Harkness, 1999) 가 어린이의 창의력에 영향을 끼칠 수 있다고 한다(Makhmalbaf and Do, 2007). 흥미는 Task를 하기 위한 동기 부여의 요인이며, 흥미와 동기를 가 짐으로 Task를 수행하고자 하는 의지가 발생하게 된다. 의 지는 창의적인 문제 해결능력의 원동력으로 본 연구에서는 흥미의 형성을 통한 동기 부여에 초점을 맞추어 Creative Tutoring Service Application을 만들고자 한다.

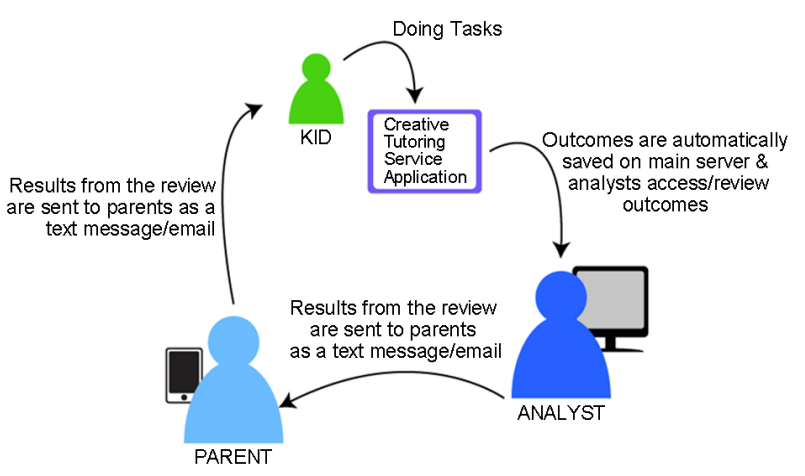

Figure 1. Creative tutoring service system flow

1) Contents: 다양한 어린이의 성향과 취향에 따른 접근 을 시도하기 위해, 이미지를 이용한 Tutoring, 스토리 텔링 
을 이용한 Tutoring, 논리적 학습을 이용한 Tutoring으로 구분지었다.

2) Reward: 보상은 Task를 지속적으로 또는 성공적으로 수행할 수 있도록 동기를 부여한다. 누적이 가능한 포인트 아이템을 제공함으로써, 아이는 타 아동을 이기기 위함이 아 닌, 자신을 상대로 좋은 결과를 위해 노력하게 될 것이다. 시 스템은 누적된 아이템을 이용하여 높은 단계의 Task로 업그 레이드하는 방식으로 진행되며, 이는 아이에게 Self-driven Task 수행능력을 키워준다. 그리하여 아이는 자기 성취감을 통해 자신감을 얻을 수 있다.

3) Feedback: 아이가 Task를 마칠 때마다 결과물을 Device에 저장을 하게 되면 자동으로 Main System으로 전송되어 Instructor가 결과물을 Review하게 된다. Review 의 결과는 부모의 Smart Phone으로 메시지의 형태로 전송 되고, 아이는 자신이 관찰되고 있다는 사실을 모르게 된다. 이에 따라 부모님은 아이들의 부정적인 측면을 치료하는 방 법에 있어서 직접적인 관여 또는, 지도 방법에 있어서 Push 하기 보다 관찰자의 입장에서, Encourage하는, 순화된 방법 으로 접근하게 된다.

\subsection{Expected effect}

1) Self-driven Growing Service: 자신이 선택한 Task 를 자신 나름의 경험을 바탕으로 해결하는 과정에서 자신을 기준으로 각각의 결과물에 대해 상대적인 평가를 내리므로, 과업 성취 유무에 대한 부담감이 적다. 그러므로 스스로 다 양한 시도를 유도할 수 있고, 게임을 하는 것과 같이, Task 성취 여부에 따른 점수 획득을 통해 동기를 부여하여 다음 단계를 위한 노력을 하게 될 것으로 예상된다.

2) Emotionally Awarded: 성공과 실패를 나누는 프로그 램이 아닌, 아이의 상상력과 생각을 표현할 수 있도록 도와 주는 것에 목적을 둔 프로그램으로 아이가 자신감 회복을 통해 새로운 시도와 환경에서도 긍정적인 감성을 갖고 적응 할 수 있는 능력을 키울 수 있다.

어린이에게 특화된 성장형 서비스를 제공할 것으로 기대 한다.

\section{Contents of Creative Tutoring Service}

\subsection{Visual association}

드로잉은 예술적 능력의 발전과 감정 표현이 동시에 가능 한 문제 해결 활동이다. 그리하여 아이들의 그림들은 심리학
에서 아이의 성향 분석, 논리적 발전, 소통의 능력, 감정 조 절, 학습능력 부진을 위한 치료들을 위한 방법으로 쓰여진다 (Makhmalbaf and Do, 2007). 이번 연구에서는 Creative Tutoring을 목적으로 함으로, 오브제를 따라 그리거나, 상황 을 재현하는 드로잉이 아닌, 추상적인 이미지를 관찰하고 자 신의 경험과 사실에 기반하여 사물의 심상을 유사성과 인접 성을 근거로 새로운 심상을 불러일으키는 시각적 연상 드로 잉을 응용한 Task를 디자인 하고자 한다. 시각적 연상 드로 잉에는 제시된 밑그림(Abstract Image)을 관찰하는 분석단 계, 밑그림을 바탕으로 다양한 형태를 시각화할 수 있는 연 상 단계, 연상한 형상(Concrete Image)을 구체화 시키는 드로잉 단계가 있다(Figure 1) (Youk and Kwon, 2011).

일반적으로 연상한 형상을 이미지로 구체화 시키는 드 로잉 단계가 최종 드로잉 단계로 마무리 되지만, Creative Tutoring Service에서는 연상된 이미지를 토대로 자신의 경 험을 기억하여 드로잉으로 구체화 시키는 Task와 2개 이상 제공된 밑그림에서 연상된 이미지들을 응용하여 밑그림들을 Crop/Copy/Paste하고 Context가 고려된 복합 연상 드로잉 의 형태로 새로운 이야기를 구성하고 구체화 시키는 Task 를 구성하여 기존 3 단계 시각적 연상 드로잉 과정에서 High Level을 추가하였다.

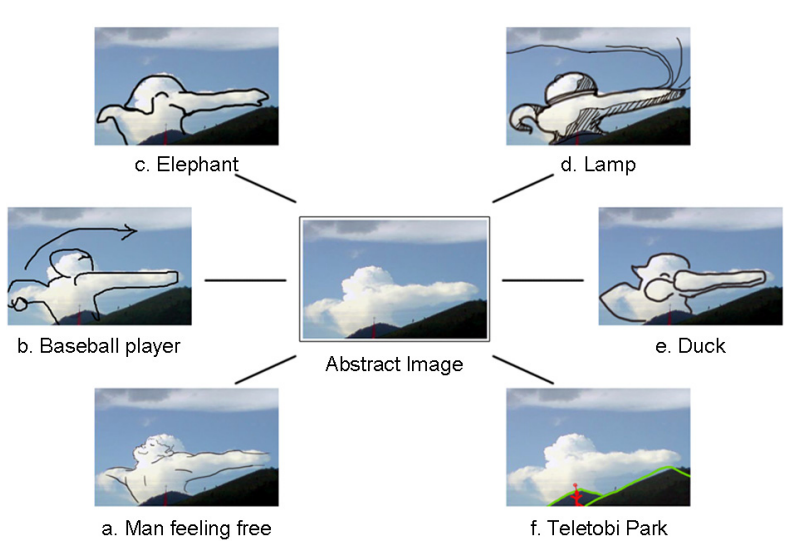

Figure 2. Visual association

6명을 대상으로 한 시각적 연상 Task 실험결과, 각각 다 른 형상을 연상하였다. 피실험자 a, b, c, d, e는 구름을 보고 자유로워하는 사람, 코끼리, 램프, 오리를 연상하였다. 피실 험자 f의 경우 구름의 이미지보다 아래 산의 이미지와 빨간 지붕을 토대로 동산과 텔레토비라는 아동용 애니메이션의 한 장면을 연상하였다. 이와 같이 같은 이미지를 기초로 하 지만 이미지 속의 대상들을 관찰하는 순서에 있어 우선순 위가 다르며, 각자의 경험을 토대로 다른 형상을 연상하게 된다. 


\subsubsection{Visualizing own memory related to a concrete image}

본 연구에서는 무의식적으로 자신의 경험을 토대로 특정 형상을 연상해내는 피실험자에게 구체적으로 특정 형상에 대한 기억이 무엇인지 질문하여 그려보도록 하였다.

1) 다음 사진을 보고 무엇이 떠오르는가요?

2) 떠오르는 것을 사진 위에 그려보세요.

3) 여러분이 그린 그림에 대한 기억에는 무엇이 있나요?

4) 떠오르는 기억을 그려보세요.

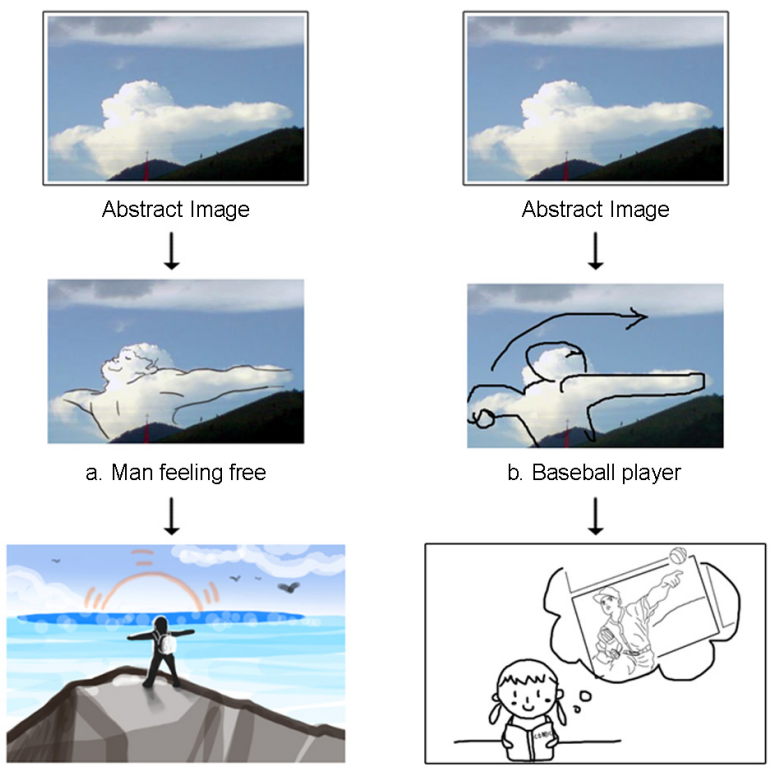

Figure 3. Upgraded visual association

피실험자 $\mathrm{a}$ 의 경우, 밑그림을 보고 자유로워하는 사람을 연상하였고, 연상된 사람의 형상과 관련된 기억을 질문하였 을 때, 여행을 가서 절벽 꼭대기에서 같은 포즈를 하고 사진 을 찍었던 기억을 떠올렸다. 또한, 특정 장면을 기억을 하면 서 바다, 바람, 햇빛과 같은 연관 대상들을 사용하여 기억을 묘사하였다. 피실험자 $\mathrm{b}$ 의 경우에는 밑그림에서 공을 던지려 는 야구선수의 모습을 연상하였고, 연상된 이미지와 관련된 기억에 대한 질문에는 야구와 관련된 만화책을 보던 기억을 떠올렸다.

아이에게 "어제 무엇을 했어?" "예전에 소풍 갔던 기억을 그려보세요"와 같이 어린이의 시각에서 막연할 수 있는 주제 를 던져주기보다, Mind map과 같이 단어들을 축출할 수 있 는 대상을 제공해줌으로써 자신에게 Task가 주어졌다는 판 단 대신 자신이 Task를 만들어 간다는 사고 방식을 만들어
줄 수 있다. 추상에서 연상으로 연상에서 기억으로 기억에서 재현의 과정을 통해 아이는 사물에서 장면, 상황을 구체화하 는 연습을 하게 된다. 이를 통해 얻어진 최종 결과물은 아이 가 자발적으로 도출해낸 것으로, 아이의 정서적 상태와 학습 상태를 평가할 수 있는 자료로 이용할 수 있다.

\subsubsection{Storytelling by re-composing given images into a new image}

사람에 따라 자신의 경험담을 애기하는 것에 대해 쑥스럽 게 생각하거나 창피하게 생각하는 경우가 있다. Storytelling 을 통해 화자는 자신의 경험과 가치관, 사고 방식을 은연 중 에 반영하게 된다. 또한, Storytelling은 총체적인 조치로 서, 우리가 컨트롤하기 힘들 수도 있는 서로의 의미 공유 나 응집력 구축 등을 유도하는 효과를 가지고 있다(Kaye and Jacobson, 1999). 일반적인 Storytelling 기법은 특정 이미지를 제시하고 그 이미지 속에서 떠오르는 이야기를 설 명하게끔 하거나, 2 개 이상의 이미지를 제공하고 피실험자가 임의로 순서를 정하여 이야기를 구성한다(Figure 4).

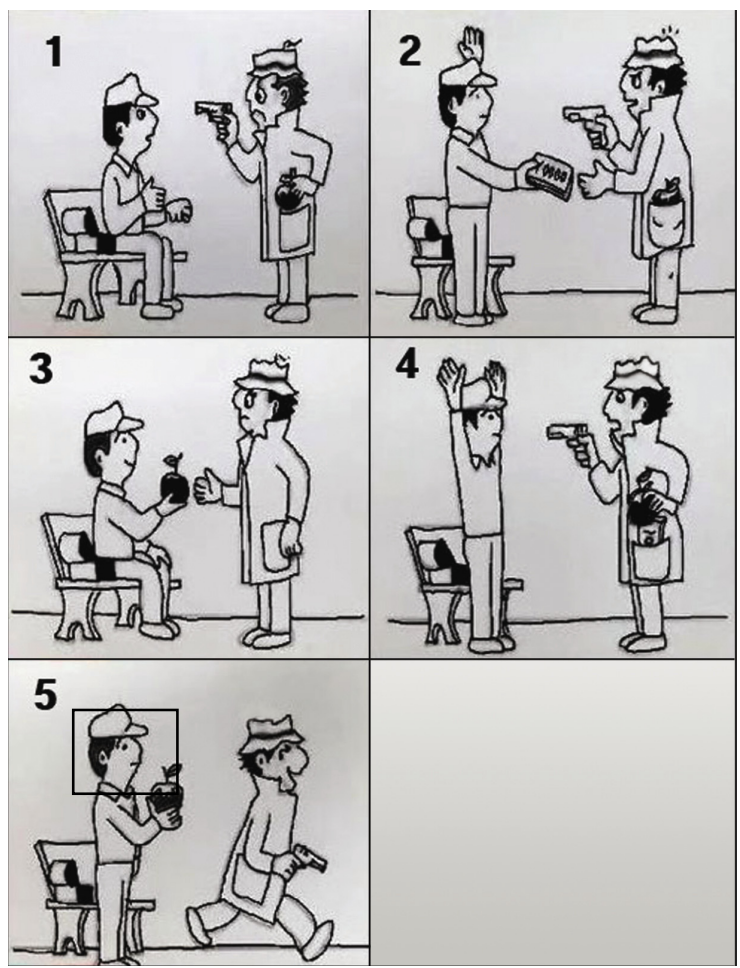

Figure 4. Storytelling sample

Creative Tutoring Service에서는 어린이가 직접 사람에 게 스토리를 만들어 읽어주는 Task가 아니라, 장난감이나 인형, 캐릭터를 의인화하여 대화를 하고 비밀을 털어놓는 아 
동 행태를 토대로, Service 자체를 이야기를 듣는 상대로 고려하거나, Service를 매개로 하여 만든 이야기를 장난감, 인형에게 설명해줄 수 있도록 돕는다. 이를 위해 어린이가 자연스러운 Storytelling을 할 수 있도록 1) 소재가 될 수 있는 이미지들을 Creative Tutoring Service에서 제공한다 (Figure 5). 2) 제공된 이미지들 속에서 어린이는 2개 이상 의 이미지들을 선택할 수 있으며(Figure 6), 3) 선택한 이미 지들의 순서를 정하여 아이는 자신만의 이야기를 만든다. 다 음 단계로 4) 선택한 이미지들 속의 사물들을 이용해 오리 기/회전하기/붙이기를 하여 5) 자신이 만들어낸 이야기의 한 장면을 새롭게 구성해보게 된다(Figure 7). 이와 같은 5 가 지 단계를 거치면서 아이는 관찰-연상-추론-상상-재구성 의 과정을 겪게 되며, 궁극적으로는 창의적 창조 활동을 하 게 된다.

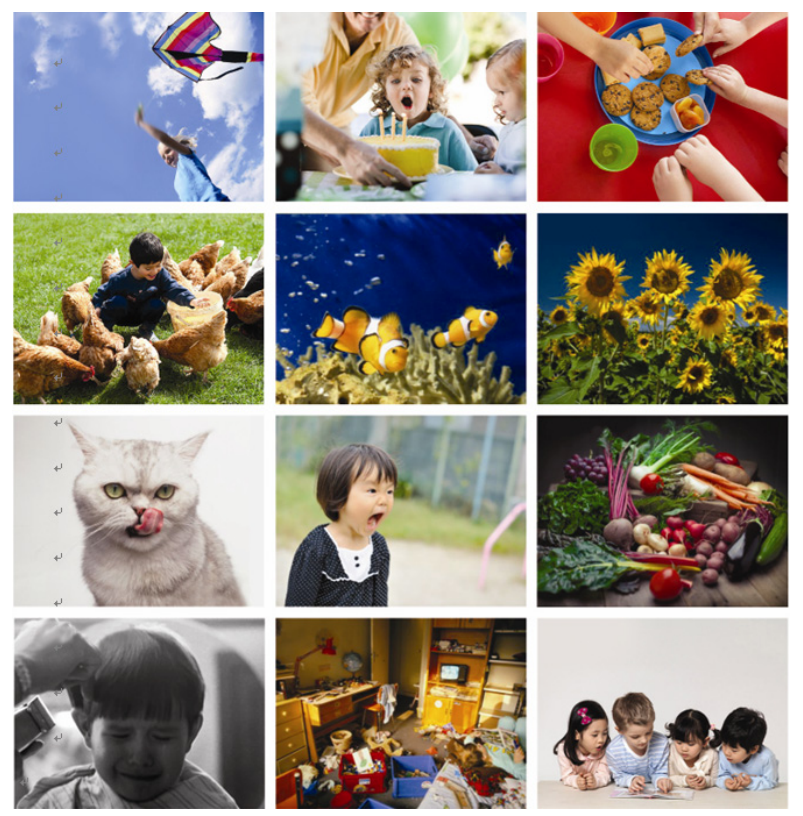

Figure 5. Step 1 - Images given from the service

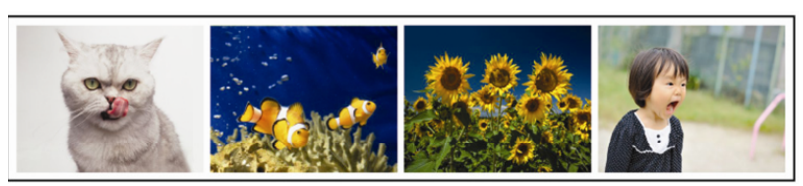

Figure 6. Step 2 - Selected images

\subsection{Learning basic math, words and music associating with synesthesia}

공감각(Synesthesia)은 어떠한 감관 영역에 따라 그 본

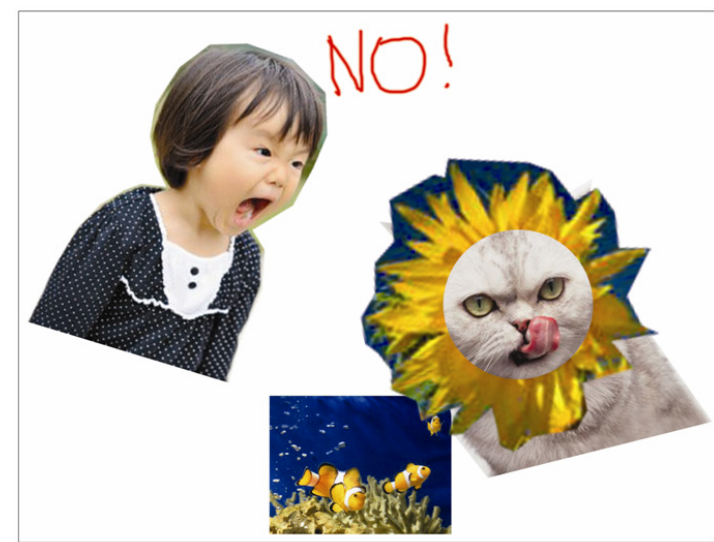

Figure 7. Step 3 - Re-composed image

래의 감각(1차 감각) 이외의 다른 양상의 감각(2차 감각)이 생기는 현상을 말하는데 예를 들면 소리를 들었을 경우에 빛 깔이 보이는 것 같은 현상을 가리킨다. 이것은 특수한 소질 에 따르는 것으로서 성인에 비하여 연소자에게 많다고 한다. 소리-냄새, 맛-빛깔 등이 여러 가지의 구성이 보고되어 있 는데, 일반적으로 2 차 감각이 시각인 경우가 많고 이를 포티 즘(Photism)이라고 한다. 미국 샌디에이고 캘리포니아대 심 리학과 빌라야누르 라마찬드란 교수는 주로 예술가나 과학 자들 가운데에는 공감각 경험자 비율이 높은 편이고, 공감각 을 이용하는 능력은 창의력과 예술성의 원천이 될 수 있다고 말한다.

칸딘스키 (Wassily Kandinsky, 1866 1944) 는 음악의 3요소 멜로디, 리듬, 화음을 색의 3요소인 색상, 명도, 채도 그리고 그림이 구성 3 요소인 점, 선, 면에 대입하여 그림을 그리는 행위를 교향악적 구성에 따라 작곡하였다고 말하였 다. 그리고 시리즈 작업 '구성', '연속' 등을 통해 음악적 미 술을 표현하고자 하였다. 그 예로 동시대의 작곡가 아놀드 쇤베르크(Arnold Schonberg, 1874 1951)의 12음기법 무 조 음악(기존 7 음을 바탕으로 한 음악이 아닌 12 가지 음을 모두 일정하게 사용하는 음악)인 피에로 1 번 '달에 취하여' 를 듣고 악기 별로 떠오르는 색을 지정하여 '구성 $\mathrm{VI}$ '를 그 려 미술에서도 음악과 같은 표현이 가능하다는 확신을 보여 주었다.

알렉산더 스크리아빈(Alexander Scriabin, 1872 1915) 는 피아니스트이자 작곡가로 신비주의 화성이라는 독창적인 화음을 만들었다. 그는 색깔을 위한 작곡을 하여 그가 작곡 한 음악을 연주할 때 음악의 흐름에 따라 무대 조명이 변하 도록 하였다. 그는 음계 도를 빨간색, 레를 노란색, 미를 하 늘색, 파\#을 보라색으로 나타내며 음정에도 색이 있다고 주 장하였다. 그는 위와 같은 색을 입힌 건반을 이용하여 소리 대신에 공연장의 화면에 빛을 연주하는 실험적인 공연을 뉴 
옥에서 하기도 하였다(1915).

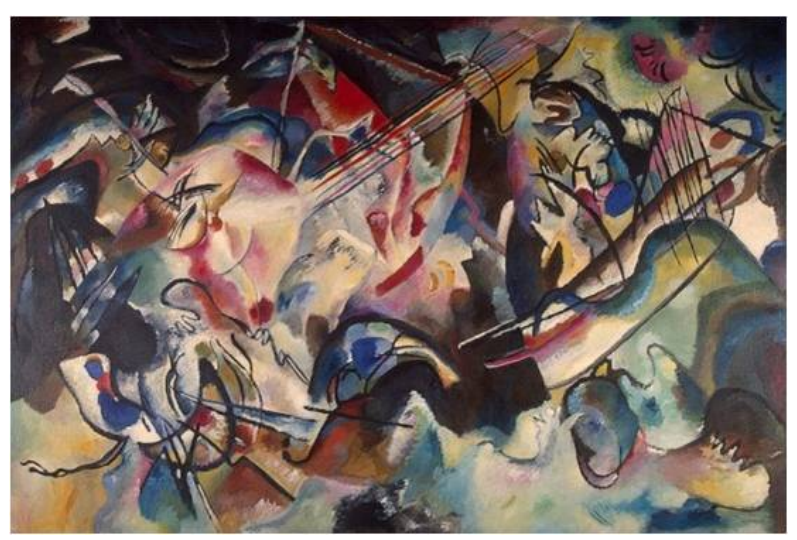

Figure 8. Composition VI, Wassily Kandinsky, 1913

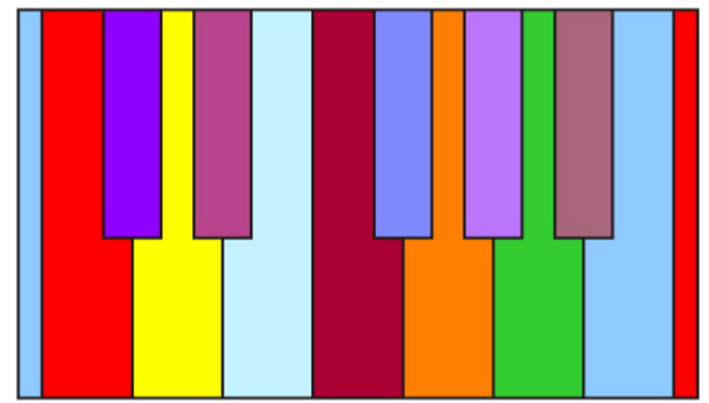

Figure 9. Colored organ designed for the performance of Scriabin's tone poem

프랑스 시인 아르튀르 랭보(Arthur Rimbaud, 1854 1891)의 경우, '모음'이라는 시에서 알파벳 $\mathrm{A}$ 는 검은색, $\mathrm{E}$ 는 초록색, $\mathrm{U}$ 는 붉은 초록, $\mathrm{O}$ 는 청색으로 비유하고 있다. 그는 글자나 숫자를 색으로 느끼면서 보았고, 글자나 숫자에서 보 이는 색을 상황으로 묘사하면서 창의적인 창작 활동을 하 였다.

이와 같이 공감각은 대상을 관찰하고 사고 및 판단을 함에 있어 자신만의 패턴을 활용하게 한다. 특히, 형태보다 인지 성이 빠른 색을 이용한 시각적 공감각을 응용하게 되면 패 턴화하기 쉬우며, 기억의 지속성을 연장할 수 있다. 또한, 다 양한 색을 이용하여 자신만의 패턴 또는 리듬을 활용한 공감 각 사고 과정은 아동에게 학습을 놀이처럼 흥미를 느낄 수 있는 활동으로 인식시킬 수 있다. 앞서 설명한 Task들이 시 각적 연상을 기반으로 한 Storytelling 드로잉 활동이었다면, 이번 Task는 시각적 연상을 방법으로 한 기초 학습에 중 점을 두어 Creative Tutoring Service Application의 예술 성과 학습성의 조화를 이루고자 하였다. 그리하여 Creative
Tutoring Service Application을 실행할 때, 어린이는 자신 의 기호에 따라 각각의 숫자와 알파벳, 자음, 모음, 음계와 같이 학습에 필요한 구성원들에 다양한 색을 지정할 수 있다 (Figure 10). 색은 같은 카테고리 안에서 반복될 수 없으나, 다른 카테고리에서는 반복될 수 있으며, 변경도 가능하다. 기초 학습 Task는 기초 산수, 기초 단어, 기초 음악으로 구 성되어 있으며, 어린이가 지정한 색으로 모든 정보가 화면에 표현된다.

\section{$+-\mathrm{x} \div=$ \\ 0123456789 ABCDEFGHIJ KLMNOPORST UVWX Z

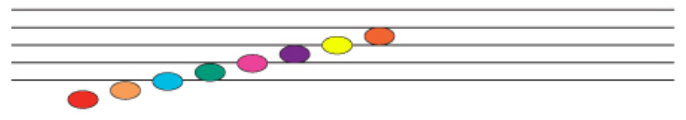

Figure 10. Example of service application setting

어린이가 스스로 색을 지정함에 따라 학습에 흥미를 높일 수 있으며, 자신이 정해놓은 규칙으로 기억하기 용이하다. 반복되는 패턴은 기호와 언어를 인지할 때 의미적 접근 이 전에, 시각적 정보로 패턴화하여 먼저 인지하기 때문에 문제 가 주어졌을 때 이해도가 빠를 것으로 예상된다.

그 예로, 2 개 이상의 숫자를 이용한 연산에 관한 문제를 제시하였을 때 아동은 + 기호와 - 기호를 색으로 인지하여 구분하여 연산의 흐름을 파악하고, 같은 숫자를 Grouping하 여 빠른 연산을 예상해볼 수 있다. 아래 예시와 같이 1) 4개 의 + 연산과 1 개의 - 연산을 파악하고, 2) + 와 - 기호의 흐름을 파악하는 과정에서 +2 와 -2 를 파악하고 0 의 결과 와 같다는 것을 도출해낸다. 그리고 3) 3 개의 숫자 1 을 빨 간색으로 찾아낸 후, + 연산을 한 결과 숫자 3 을 도출해내 고, 4)나머지 숫자 3 을 더해 최종적으로 숫자 6 의 결과물을 얻게 된다(Figure 11).

기초 언어에서는 1) Desert 그리고 Dessert와 같이 유사 한 발음, 유사한 알파벳의 구성에서 알파벳 반복의 차이를 가진 경우, 2) Male 그리고 Mail과 같이 유사한 발음이지만 전혀 다른 알파벳 구성을 가진 경우, 2) Now 그리고 Know 
와 같이 묵음 알파벳이 추가된 알파벳 구성을 가진 경우와 같이 자주 혼돈되는 Spelling을 색, 그리고 색이 가진 리듬 을 이용하여 아이가 지속적으로 기억할 수 있는 다양한 단서 를 만들어 줄 수 있다(Figure 12).

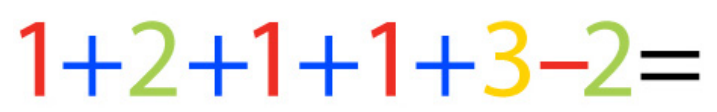

Figure 11. Example of basic learning task_math
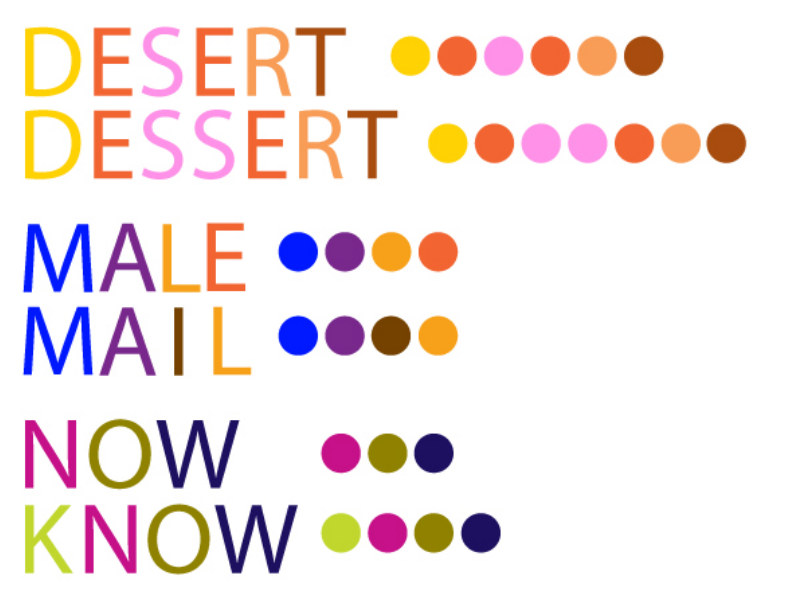

Figure 12. Example of basic learning task_word

기초 음악에서는 각 음계가 오선지 위에서 가지는 위치를 인지하는 것보다 음계 별로 색을 입히는 경우 인지의 속도가 빠르며, 악보 뿐만이 아니라, 그림 또는 풍경, 감정과 같이 다양한 컨텐츠를 음악으로 Transfer하거나 반대로 음악을 시각화할 수 있다. 아래 Figure 13은 동요 '반짝 반짝 작은 별'의 첫 음절을 오선지에 색으로 표현한 것으로써, 아동이 악보에 흥미를 갖고 읽을 수 있는 능력을 키워줄 수 있다. 또한 Type A나 Type A'와 같이 자신만의 패턴을 머리 속 으로 그리는 것과 같이 다양한 패턴으로 악보를 재해석하는 것도 창의적인 악보읽기 능력으로 볼 수 있다.
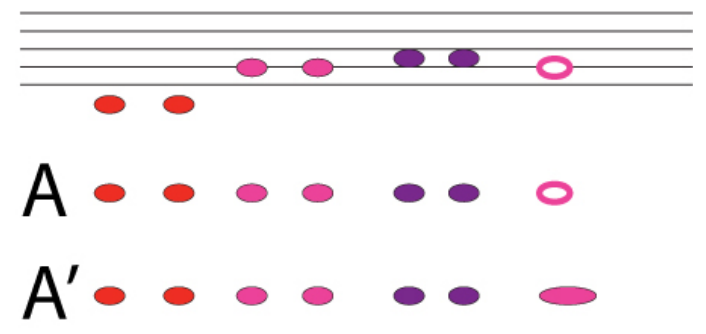

Figure 13. Example of basic learning task_music

\section{Results}

어린이들은 '아, A가 B와 닮았다!', '나도 A 갖고 있는데' 와 같이 자신이 경험한 것에 대해서 주변의 사물 또는 상황 에서 유사점을 찾으려고 하며, 유사성에서 유대감을 갖게 된 다. 또한, '내 것은 이 부분이 다른 색이야', '어! 나는 $\mathrm{A}$ 를 먹었는데'와 같이 다른 점을 찾기도 한다. 이와 같이 주어진 대상에 대해 경험을 기반으로 토대로 연상작용을 하는 것 을 반복하면서 스스로 학습해 나간다. 그리하여 Creative Tutoring Service Application에서 제공된 추상적인 이미 지는 더욱 다양한 시각적 추론을 가능하게 하며, 아이는 자 신이 알고 있는 것 즉, 경험해본 것을 토대로 새로운 이미지 를 추론해내게 된다. 추론된 이미지를 단서로 하여 아이의 구체적인 경험담을 물어보게 됨으로써 아이는 단서를 토대 로 이야기를 상상하고 구체화시키는 활동을 하게 되고, 그 이야기를 다시 장면의 그림으로 표현하면서 창의력을 키우 게 된다. 또한, 시각적 공감각을 응용한 기초 학습을 하면서 주어진 문제를 푸는 것 이상으로, 자기 스스로가 재조합 및 구성을 하면서 스스로 도전하고 해결해나가는 패턴을 습득 할 수 있다. 직접 단서(Hint) 보다는 추상적이고, 공감각적인 간접 단서(Clue)를 제공해줌으로써 아이의 창의적인 문제해 결 능력과 감성적인 사고 방식을 키울 수 있고, 간접 단서가 제시됨으로써 아이는 막연하게 질문에 답을 해야 한다거나 빈 곳을 채워야 한다는 부담감, 불안감을 줄일 수 있다.

\section{Conclusion}

어린이들을 위한 서비스 디자인을 할 때에는 어린이들이 특정 환경에서 Task를 받고 수행해 나가는 과정에서 어떻 게 생각하는지, 그리고 다양한 상황에서 자기 스스로를 어떻 게 판단하고 평가를 내리는지를 이해하는 것이 가장 중요하 다. 어린이가 특정 결과물을 도출해내거나 특정 내용을 학습 하는 것에 초점을 맞추기 보다, 아이의 성향을 살리면서 창 의적인 결과물을 도출해내도록 유도할 수 있는 방법과 과정 에 중점을 둠으로써 본 Creative Tutoring Service는 어린 가 새로운 것을 시도하는 것에 대해 받는 스트레스를 줄이 고 조금 더 자신의 생각을 표현할 수 있도록 돕고 있다. 또 한, 개인의 Smart Device를 이용한 서비스를 이용함으로써 다른 아이들과 비교될 것이라는 불안감을 제거시키고 스스 로도 할 수 있다는 자신감을 가지게 된다.

어린이들은 찰훍과 같은 존재이다. 무한한 가능성을 갖고 있고, 환경에 따라 예측할 수 없는 성향을 보이게 된다. 그 
러므로 Creative Tutoring의 필요성과 방법에 있어서 다양 한 환경에 있는 어린이들과 함께 심도 있게 지속적으로 연 구가 이루어 져야 한다.

\section{References}

Alexander Scriabin, Wikipedia, http://en.wikipedia.org/wiki/Scriabin (retrieved December 28).

Cho, J. H., Children's Perception of Self-competence and Stress Affection Learned Helplessness, Kye Myung University, 2003.

Dan Perjovschi; improvisational artist, his works like jazz, Designdb, http://designdb.com/dreport/dblogView.asp?gubun=0\&catPKID=\&s $\mathrm{Gb}=\& \mathrm{sTxt}=\& \mathrm{oDm}=3 \& b b s T y p e=\&$ page $=1 \& b b s P K I D=20146$ \#head s\&bbsPKID=20146(retrieved December 23).

Kaye, B. and Jacobson, B., True Tales and Tall Tales; The Power of Organizational Storytelling, Training \& Development, 2, 1999.

Kim, M. J., A Study on Visual Art through the Sense of Smell, Kyon Ggi University, 2009.

Lee, E. B., Kim, W. K. and Kim, S. P., Korean Literature Dictionary, Korea Dictionary Research, 1994.

Makhmalbaf, A. and Do, E. Y., Physical Environment and Creativity: Comparing Children's Drawing Behavior at Home and at The Bookstore, International Association of Societies of Design Research, 2007.

Ro, O. K., Relationship between the Coping Style with Study Stress and the Learning Motivation, Kyung Won University, 2009.

Youk, E. J. and Kwon, D. Y, A Creative Drawing Process Using Visual Association, Journal of Digital Interaction Design, Vol. 10, No. 1, 107-119, 2011
Vilayanur S. Ramachandran, Wikipedia, http://en.wikipedia.org/wiki/ Vilayanur_S._Ramachandran (retrieved December, 28)

\section{Author listings}

Dong Min Lee: mick@khu.ac.kr

Highest degree: MFA, 3-D Design, Cranbrook Academy of Ar Position title: Professor, Department of Industrial Design, Kyung Hee University

Areas of interest: UCD, UI, UX, HCI

Hye Jung Park: hyejunghennypark@gmail.com

Highest degree: MFA, Department of Furniture Design, Rhode Island School of Design

Position title: Senior Manager, Smart Solution Lab, FEIT Creative Solution Group

Areas of interest: User Experience, Context Design, HCI

Sung Bae Cho: joe@feit.co.kr

Highest degree: Ph.D candidate, Design Studies, Myong gi University Position title: Instructuor, Department of Industrial Design, Kyung Hee University

Areas of interest: UCD, UX, GUI

Date Received : 2011-12-30

Date Revised :2012-01-16

Date Accepted : 2012-01-21 